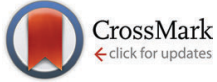

Cite this: Phys. Chem. Chem. Phys., 2016, 18, 7374

Received 5th January 2016 Accepted 8th February 2016 DOI: $10.1039 / \mathrm{c} 6 \mathrm{cp} 00065 \mathrm{~g}$

www.rsc.org/pccp

\title{
Degradation mechanism of a high-performance real micro gas sensor, as determined by spatially resolved XAFS $\dagger$
}

\author{
Takahiro Wada, ${ }^{\text {ab }}$ Naoyoshi Murata, ${ }^{\mathrm{C}}$ Hiromitsu Uehara, ${ }^{\mathrm{C}}$ Takuya Suzuki, \\ Hiroaki Nitani, ${ }^{d}$ Yasuhiro Niwa, ${ }^{d}$ Motohiro Uo ${ }^{a}$ and Kiyotaka Asakura*e
}

\begin{abstract}
Of late, battery-driven high-performance gas sensors have gained acceptability in practical usage, whose atomic-scale structure has been revealed by $\mu$-fluorescence $\mathrm{X}$-ray absorption fine structure analysis. We studied the chemical distribution of $\mathrm{Pd}$ species in the $\mathrm{Pd} / \mathrm{Al}_{2} \mathrm{O}_{3}$ catalyst overlayer in the real gas sensor at various degrees of deterioration. In a freshly prepared sensor, all Pd species were in the $\mathrm{PdO}$ form; in a heavily deteriorated sensor, $\mathrm{Pd} / \mathrm{Al}_{2} \mathrm{O}_{3}$ in the external region changed to metallic $\mathrm{Pd}$ particles, while the $\mathrm{PdO}$ structure in the inner region near the heater remained unchanged. The Pd species distribution was in agreement with the simulated thermal distribution. Temperature control was crucial to maintain the high performance of the gas sensor. The improved sensor allows homogeneous heating and has a lifetime of more than 5 years.
\end{abstract}

\section{Introduction}

Natural gas is now used as a household energy resource because it is user- and environment-friendly with low $\mathrm{CO}_{2}$ emission. In 2011 , natural gas was used for $1 / 5$ th of residential energy consumption in Japan. ${ }^{1,2}$ For further spreading the use of natural gas as a residential energy resource, safety measures such as a gas-leakage sensor should be developed. $\mathrm{SnO}_{2}$ is the most important sensor material for such a purpose, because its electric conductivity changes with the gas composition at high temperatures. ${ }^{3}$ When reductive gases (such as methane, hydrogen, alcohol, and carbon monoxide) are present, the surface oxygen content decreases and more conduction electrons are created so that the gas conductivity increases. High temperatures are necessary for this surface reaction to occur and an AC power supply is required for heating the gas sensor. Moreover, the AC power supply hinders

\footnotetext{
${ }^{a}$ Graduate School of Medical and Dental Sciences, Tokyo Medical and Dental University, Tokyo 113-8549, Japan

${ }^{b}$ ICAT Research Fellow, Institute for Catalysis, Hokkaido University, Sapporo 001-0021, Japan

${ }^{c}$ Corporate R \& D Headquarters, Fuji Electric Co., Ltd, Tokyo 191-8502, Japan

${ }^{d}$ Photon Factory, Institute of Materials Structure Science, High Energy Accelerator Research Organization (KEK), Tsukuba 305-0801, Japan

${ }^{e}$ Institute for Catalysis, Hokkaido University, Sapporo 001-0021, Japan.

E-mail:askr@cat.hokudai.ac.jp

$\dagger$ Electronic supplementary information (ESI) available: Fig. S1: calculation of the volume of the central and peripheral regions. Fig. S2: simulation results of the temperature distribution of the $\mathrm{Pd} / \mathrm{Al}_{2} \mathrm{O}_{3}$ overlayer. Fig. S3: the normalized Pd K-edge XANES spectra of Pd foil, PdO and the $\alpha$ position with various deterioration degrees. See DOI: 10.1039/c6cp00065g
}

the daily use of the $\mathrm{SnO}_{2}$ gas sensor for domestic purposes because of the limited installation sites in a house and its bulkiness. Therefore, it is desirable that a battery-driven gas sensor with a long lifetime should be developed.

Suzuki et al. developed a new $\mathrm{SnO}_{2}$ battery-driven sensor using a micro electro mechanical system (MEMS) to achieve low power consumption. ${ }^{4,5}$ The key factors of this MEMS are the use of catalysts and a pulsed heating system. The new batterydriven $\mathrm{SnO}_{2}$ sensor has a multilayer structure composed of a $\mathrm{Pd} / \mathrm{Al}_{2} \mathrm{O}_{3}$ catalyst overlayer, a $\mathrm{Pt}-\mathrm{SnO}_{2}$ catalyst layer, a $\mathrm{SnO}_{2}$ sensor layer, an electrode, and a heater, which are sequentially deposited on a Si chip, affording the sensor high sensitivity and selectivity for methane-the main ingredient of natural gas. In particular, $\mathrm{Pd} / \mathrm{Al}_{2} \mathrm{O}_{3}$ increases the selectivity of the sensor for methane. ${ }^{6}$ Murata et al. developed a model sensor on a few- $\mathrm{cm}^{2}$ Si substrate, where a $\mathrm{SnO}_{2}$ thin layer and $\mathrm{Pt}-\mathrm{SnO}_{2}$ and $\mathrm{Pd} / \mathrm{Al}_{2} \mathrm{O}_{3}$ layers were deposited sequentially on the substrate. They characterized the structure under in situ conditions, where the sample was heated to high temperature in a flow of hydrogen or methane gas, using an X-ray absorption fine structure (XAFS). ${ }^{7,8}$ They found that their model sensor comprised atomically dispersed $\mathrm{Pt}$ in $\mathrm{SnO}_{2}$, which was the active species that enhanced the sensor activity, and that $\mathrm{PdO}$ was present in the $\mathrm{Pd} / \mathrm{Al}_{2} \mathrm{O}_{3}$ catalyst overlayer and it increased the methane sensitivity of the sensor.

The selectivity of the sensor for methane decreased during the operations. Therefore, the lifetime of the battery-driven sensor was shorter than that of the battery itself. In order to understand the origin of the deterioration mechanism of the sensor, we characterized the structure of a real micro gas sensor 
using a $\mu$-fluorescence X-ray absorption fine structure ( $\mu$-XAFS), with the spatial resolution in the order of a few tens of $\mu \mathrm{m}$. The $\mu$-XAFS with $\mu \mathrm{m}$ or nm resolution has been applied to various fields, e.g. catalysis $^{9-13}$ and biomedical, ${ }^{14-17}$ geological and environmental sciences. ${ }^{18-20}$ In our previous report we found that PdO particles in the fresh $\mu$-gas sensor were reduced to Pd metal as the methane selectivity decreased. ${ }^{13}$ Based on these results, we inferred that the Pd metal formation was responsible for the deterioration of the sensor performance. We had a question: why the methane selectivity was completely lost when the sensor still had plenty of PdO species? In order to answer this question, we further investigated the Pd structure and its change in each part of the $\mathrm{Pd} / \mathrm{Al}_{2} \mathrm{O}_{3}$ overlayer present in the $\mu$-gas sensor. We measured the Pd K-edge $\mu$-XAFS using a micro beam and found that the Pd metal particle was not homogeneously distributed in the $\mathrm{Pd} / \mathrm{Al}_{2} \mathrm{O}_{3}$ overlayer. We determined the distribution of $\mathrm{PdO}$ and the $\mathrm{Pd}$ metal inside the $\mathrm{Pd} / \mathrm{Al}_{2} \mathrm{O}_{3}$ overlayer in the deteriorated sensor chip. In this paper, we discuss the origin of the loss of the methane selectivity of a high-performance $\mu$-gas sensor and the importance of homogeneous heating in the $\mu$-gas sensor.

\section{Experimental}

\subsection{Samples}

The $\mu$-gas sensors were prepared as described in previous reports. ${ }^{4,5,7,13,21,22}$ The sample was heated by a pulsed heating system. When the sample was heated inhomogeneously, its selectivity decreased with time; however, when it was homogeneously heated at $703 \mathrm{~K}$, its selectivity was not hampered. The overall Pd structure has been reported in a previous paper. ${ }^{13}$ The samples were subjected to a flow of $500 \mathrm{ppm}_{2}$ and $99 \%$ relative humidity $(\mathrm{RH})$, which were more severe operation conditions than general operation conditions. Selectivity (Sel) is defined as follows:

$$
\text { Sel }=R_{\text {hydrogen }} / R_{\text {methane }}
$$

where $R_{\text {hydrogen }}$ and $R_{\text {methane }}$ are the resistance in $1000 \mathrm{ppm} \mathrm{H}_{2}$ and $\mathrm{CH}_{4}$ flow, respectively, at $20{ }^{\circ} \mathrm{C}$ and $65 \%(\mathrm{RH})$. Four typical samples, fresh $(\mathrm{Sel}=5.2)$, Sel $3.7(\mathrm{Sel}=3.7)$, Sel $1.8(\mathrm{Sel}=1.8)$, and Sel $0.9(\mathrm{Sel}=0.9)$, were prepared for $\mu$-XAFS measurements.

\subsection{XAFS measurements}

Pd K-edge $\mu$-XAFS experiments were performed at the NW-10A beamline at the Photon Factory (Institute for Materials Structure Science, High Energy Accelerator Research Organization, KEKIMSS-PF) using a Si(311) double-crystal monochromator in the fluorescence mode. ${ }^{23}$ The original beam size of this beam line was $1 \mathrm{~mm} \times 1 \mathrm{~mm}$. The X-ray beam was further focused by a polycapillary lens having a focal distance of $9.5 \mathrm{~mm}$ and a transmission efficiency of $\sim 8 \%$ at $25 \mathrm{keV}$ (XOS Inc., USA), as described in a previous paper. ${ }^{13}$ The incident X-ray beam intensities were monitored by a $170 \mathrm{~mm}$-long ionization chamber. The X-ray fluorescence was detected by a 19-element germanium solid state detector (Ortec, USA). The focal spot was about $25 \mu \mathrm{m}$ in diameter

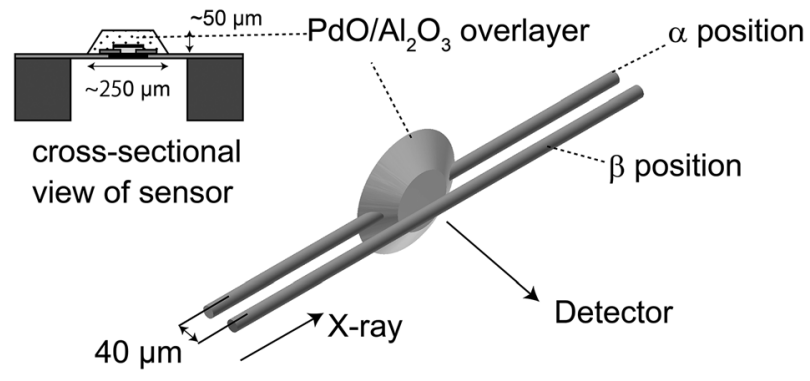

Fig. 1 Alignments of a micro beam and a $\mu$-gas sensor. The sample was mounted parallel to the $X$-ray incident direction. The cross section area of the X-ray is $25 \mu \mathrm{m}$ in diameter, and its FWHM is measured by knife edge scan.

(full-width at half-maximum, FWHM) measured by knife-edge scans. The XAFS spectra were analyzed using the REX2000 software (Ver. 2.5, Rigaku, Japan). ${ }^{24}$

We set the X-ray parallel to the sensor base denoted as the $\alpha$ position (shown in Fig. 1), where the maximum-fluorescence $\mathrm{X}$-ray intensity was obtained. In the $\alpha$ position, X-ray passes through the $\mathrm{Pd} / \mathrm{Al}_{2} \mathrm{O}_{3}$ overlayer. Since the beam size was a little less than the thickness of the $\mathrm{Pd} / \mathrm{Al}_{2} \mathrm{O}_{3}$ overlayer $(40 \mu \mathrm{m})$, we shifted the sensor by $40 \mu \mathrm{m}$ to ensure the beam glances the top surface region, as shown in Fig. 1 (denoted as the $\beta$ position). We also set the incidence X-ray direction at $45^{\circ}$ with the chip surface. We allowed the X-ray to pass through the central region which gives maximum-fluorescence X-ray intensity, with its position denoted as the $\gamma$ position. The beam was shifted by $100 \mu \mathrm{m}$ to pass it through the peripheral region of the $\mathrm{Pd} / \mathrm{Al}_{2} \mathrm{O}_{3}$ overlayer (donated as the $\delta$ position), as shown in Fig. 2.

\section{Results}

Fig. 3-6 show the X-ray absorption near-edge structure (XANES) spectra at various degrees of degradation in $\alpha, \beta, \gamma$, and $\delta$ positions, respectively. In the Sel 5.2 sample (fresh sample), Pd was in the PdO form in all X-ray positions ( $\alpha, \beta, \gamma$, and $\delta$ positions).

The XANES spectra in $\beta$ and $\delta$ positions changed with the change in the degree of degradation. The first edge peak $(24350 \mathrm{eV})$ decreased in intensity while the new structure appeared at the higher-energy side (24375 eV). Fig. 4 shows the XANES spectra of the $\beta$ position with different degradation degrees. As mentioned

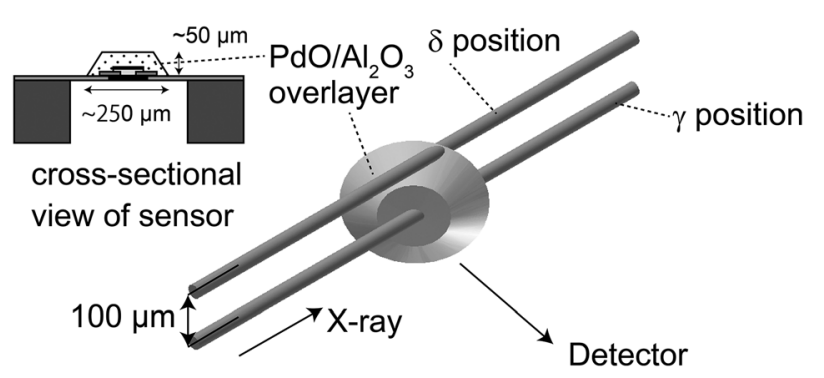

Fig. 2 Alignments of an X-ray $\mu$-beam and a $\mu$-gas sensor. The sample was mounted vertically at $45^{\circ}$ of the incident $X$-ray direction. 


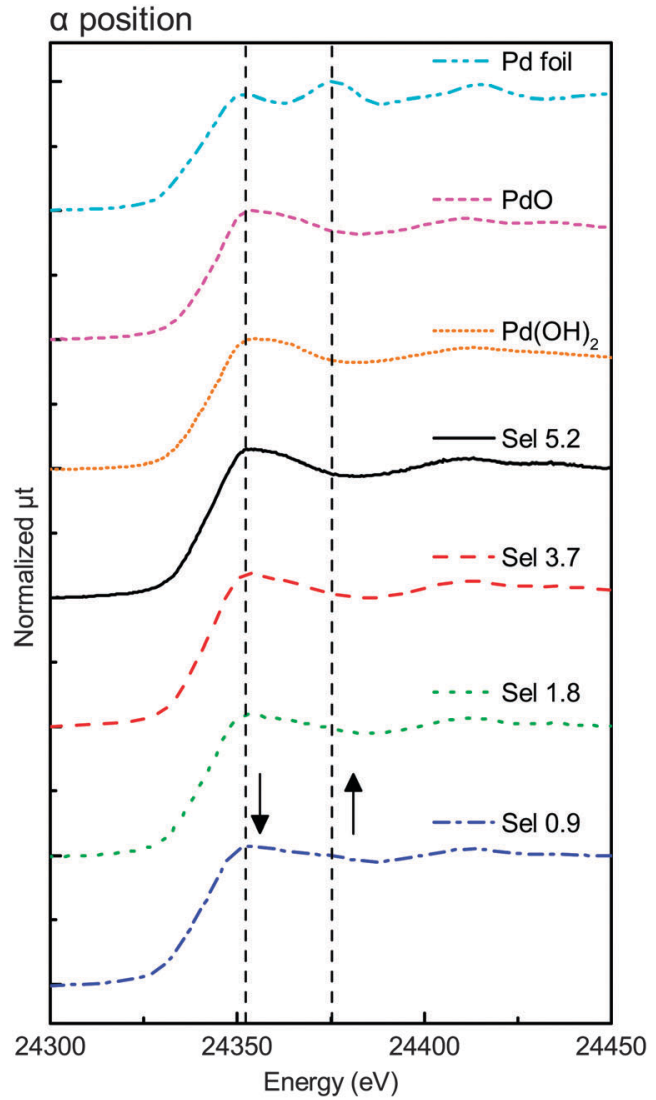

Fig. 3 Pd K-edge XANES spectra of the $\alpha$ position with various deterioration degrees.

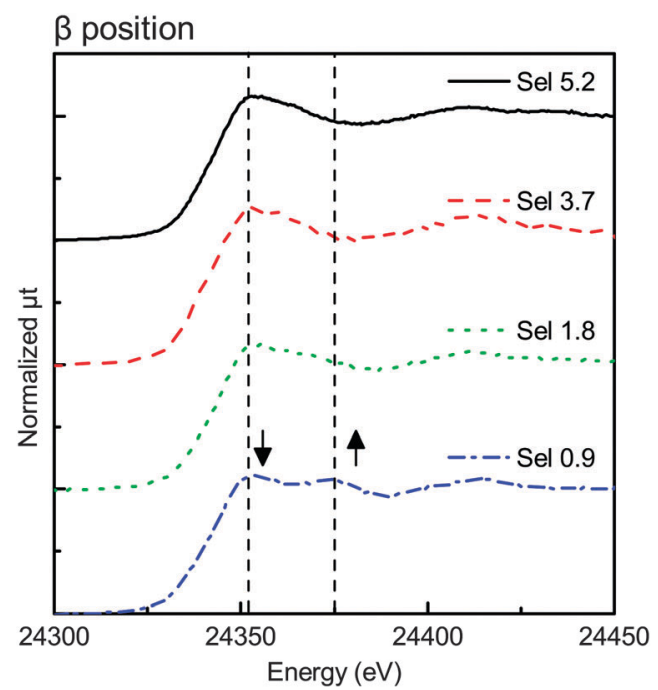

Fig. 4 Pd K-edge XANES spectra of the $\beta$ position with various deterioration degrees.

above, the peak at $24350 \mathrm{eV}$ decreased in intensity with the increase of the peak at $24375 \mathrm{eV}$. The XANES spectra of the Sel 0.9 sample had a feature characteristic of Pd foil.

On the other hand, Fig. 3 and 5 show no remarkable change in the XANES spectra, indicating that the Pd species were mostly

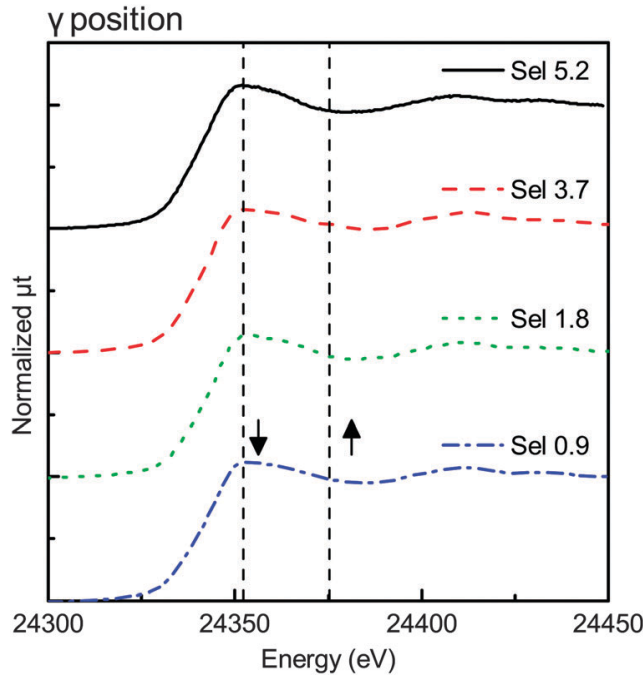

Fig. 5 Pd K-edge XANES spectra of the $\gamma$ position with various deterioration degrees

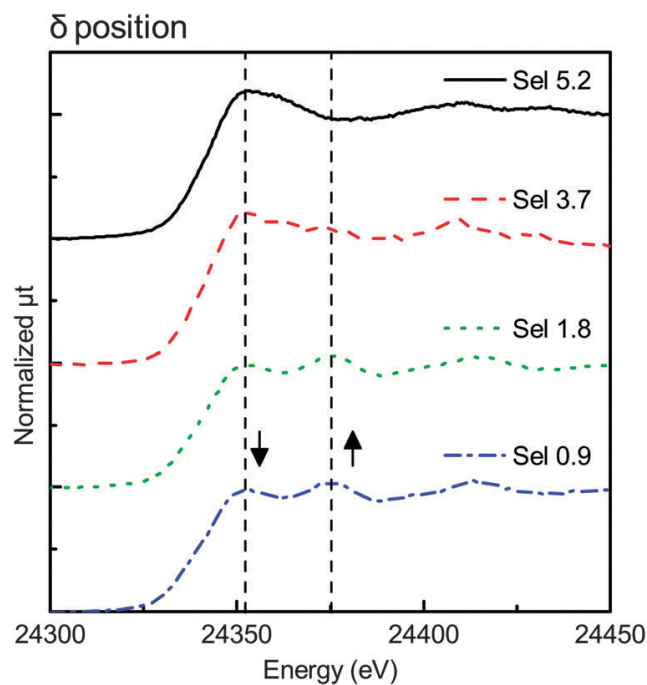

Fig. 6 Pd K-edge XANES spectra of the $\delta$ position with various deterioration degrees.

in the PdO state in the $\alpha$ and $\gamma$ positions. Although Fig. 5 shows little change in the spectra, the spectra in Fig. 3 had a small shoulder at $24375 \mathrm{eV}$, probably due to Pd metal in the $\alpha$ position. The change was observed only in the $\alpha$ position, indicating that the effect of the top surface region could be neglected because the thickness of the reduced metal portion on the top surface region was smaller than that of the reduced metal portion on the peripheral region.

We carried out deconvolution analysis of the XANES spectra in the $\alpha$ position, where the spectra were composed of those of the central and peripheral regions. Assuming that the effect of the top surface region was negligible on the XANES spectra of the $\gamma$ position, the XANES spectra at the body could be approximated as those of the $\gamma$ position. The XANES spectra at the peripheral region could be considered equal to those of the 
$\delta$ position. The spectra at the $\alpha$ position could be expressed as shown in eqn (1):

$$
\begin{gathered}
\mu_{\alpha}(E)=a \times \mu_{\gamma}(E)+(1-a) \times \mu_{\delta}(E) \\
1 \geqq a \geqq 0
\end{gathered}
$$

where $\mu_{\alpha}(E), \mu_{\gamma}(E)$, and $\mu_{\delta}(E)$ are the spectra in the $\alpha, \gamma$, and $\delta$ positions, respectively. Applying the least-squares method for all samples with a single value of $a$, we found that $a=0.7$ for Sel 0.9 and Sel 1.8. We could not calculate $a$ for Sel 3.7 and Sel 5.2 because the reduction amounts were too small.

Fig. S1(a) and (b) (ESI $\dagger$ ) show the three- (3D) and twodimensional (2D) rough sketches of the $\mathrm{Pd} / \mathrm{Al}_{2} \mathrm{O}_{3}$ overlayer on the gas sensor. The distance between the $\delta$ and the $\gamma$ positions is $\sim 100 \mu \mathrm{m}$ and the micro-beam spot is $25 \mu \mathrm{m}$ in diameter, as shown in Fig. S1(c) (ESI $\dagger$ ). Considering these positions, we defined the peripheral region as the dark-shaded ridge, as shown in Fig. S1 (ESI $\dagger$ ), and the rest was defined as the center region, as shown in Fig. S1(d) (ESI $\dagger$ ). Fig. S1(e) (ESI $\dagger$ ) shows the $3 \mathrm{D}$ sketch of the central and the peripheral regions. Based on this rough assumption about the peripheral and the central regions, we calculated the contribution of these regions to X-ray absorption. The path lengths for the central and peripheral regions were $\sim 160$ and $\sim 80 \mu \mathrm{m}(=40 \mu \mathrm{m} \times 2)$, respectively, where both the peripheral regions are considered.

$$
a=80 / 240=0.66
$$

The value of $a(0.66)$ is consistent with that calculated from eqn (1) and (2) by the least-squares method $(a=0.7)$. Fig. 7 and 8 show the comparison of the XANES spectra between the spectra observed at the $\alpha$ position and the spectra synthesized using the spectra of the $\gamma$ and $\delta$ positions with appropriate

\section{Sel 0.9}

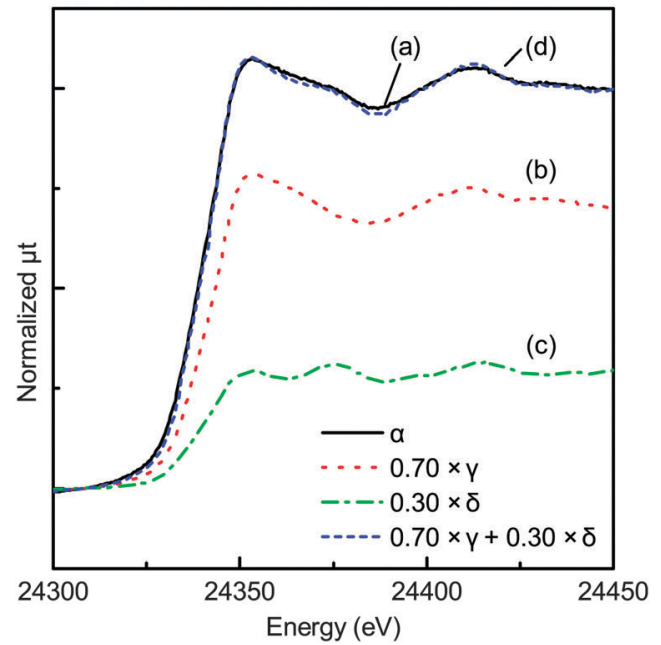

Fig. 7 Comparison of the XANES spectra between the observed spectrum of the $\alpha$ position and the synthesized spectrum using $\gamma$ and $\delta$ positions' spectra with appropriate weights $(a=0.7)$. The XANES spectra were of a treated sample (Sel 0.9) of the (a) $\alpha$ position, (b) $\gamma$ position (70 at\%), (c) $\delta$ position (30 at\%), and (d) synthesized result.
Sel 1.8

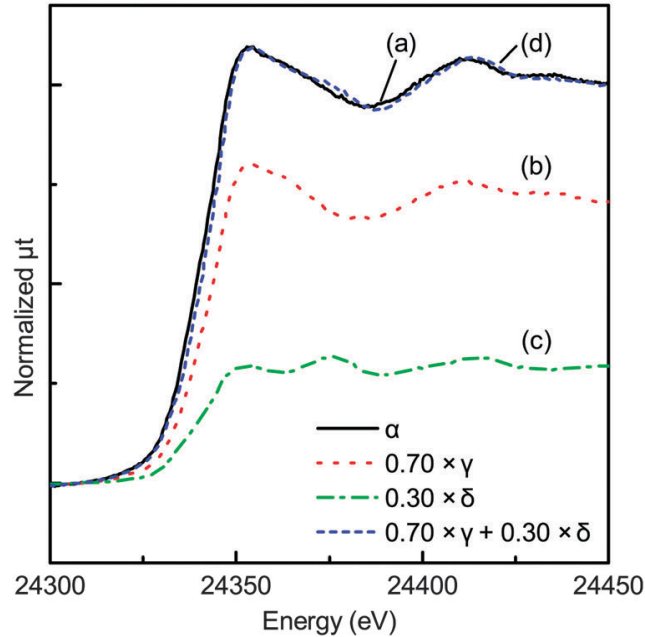

Fig. 8 Comparison of the XANES spectra between the observed spectrum of the $\alpha$ position and the synthesized spectrum using $\gamma$ and $\delta$ positions spectra with appropriate weights $(a=0.7)$. The XANES spectra were of a treated sample (Sel 1.5) of the (a) $\alpha$ position, (b) $\gamma$ position (70 at\%), (c) $\delta$ position (30 at\%), and (d) synthesized result.

weights $(a=0.7)$. This means that the definitions of the central and peripheral regions are approximately correct.

In addition to the peripheral region, the XAFS spectra in the $\beta$ position show that the thin top surface region on the top of the gas sensor was also reduced. The X-ray was irradiated on the sample under glancing conditions to weaken the signal, but the spectra showed that PdO was reduced as the deactivation proceeded. Considering that the metal component was absent in the spectrum in the $\gamma$ position, the thickness of the top surface region might be less than $1 \mu \mathrm{m}$.

As a result, the $\mathrm{Pd} / \mathrm{Al}_{2} \mathrm{O}_{3}$ overlayer is roughly divided into 3 regions: the central region, the peripheral region, and the thin top surface region.

Fig. 9 shows the XANES of Sel 0.9 on each X-ray position. Only the spectrum in the $\gamma$ position, corresponding to the central position, was similar to that of PdO and those in the $\beta$ and $\delta$ positions were like the spectra of Pd foil rather than those of PdO, which in turn corresponded to the top surface and the peripheral regions, respectively.

Table 1 shows the metallic Pd content of each sample calculated from the linear combination fitting of the Pd K-edge XANES spectra of Pd foil and PdO. We carried out two-component regression analysis since we found isosbestic points in the spectra shown in Fig. S3 (ESI $\dagger$ ) though there were possibilities for the presence of other Pd oxide species. The errors in these calculations were estimated using the Hamilton ratio method at a confidence level of $95 \% .^{25}$ In the Sel 5.2 sample, we found PdO in all regions. The selectivity decreased with the increase of the metallic Pd content in the peripheral and the top surface regions.

The average values of the metallic Pd content were calculated in the sample. Since the thickness of the top surface region was too small, metallic Pd contents in the two regions were averaged 


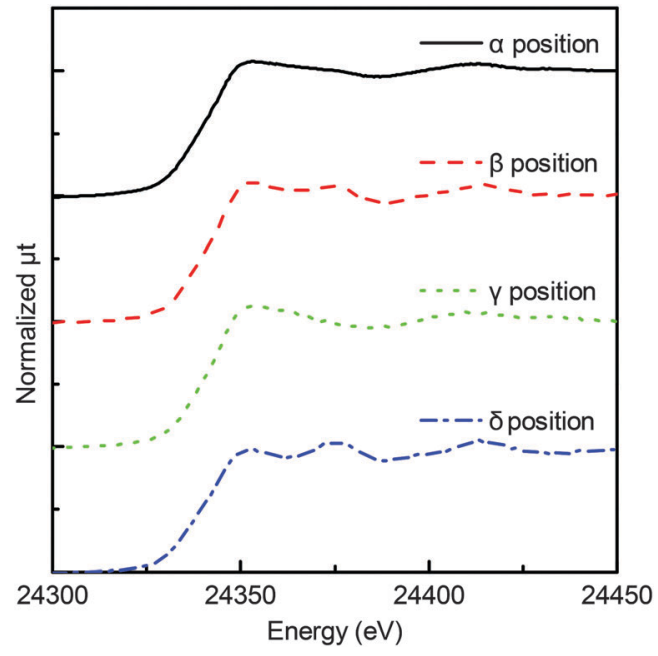

Fig. 9 Pd K-edge XANES spectra of Sel 0.9 of each position.

Table 1 Metallic Pd ratio of each alignment of the samples calculated from the linear combination fitting of Pd $\mathrm{K}$ edge XANES spectra

\begin{tabular}{lcrcc}
\hline Target region & Top surface & \multicolumn{1}{c}{ Bulk } & Peripheral & \multicolumn{1}{c}{ Average } \\
\hline Fresh (Sel 5.2) & $0 \pm 3$ & $0 \pm 2$ & $0 \pm 3$ & $0(2 \pm 3)$ \\
Sel 3.7 & $3 \pm 7$ & $18 \pm 3$ & $18 \pm 9$ & $18 \pm 5(14 \pm 3)$ \\
Sel 1.8 & $13 \pm 4$ & $5 \pm 4$ & $86 \pm 4$ & $29 \pm 4(23 \pm 4)$ \\
Sel 0.9 & $48 \pm 5$ & $12 \pm 3$ & $83 \pm 4$ & $36 \pm 6(38 \pm 5)$
\end{tabular}

based on their volumes calculated from the 3D model, as shown in Fig. S1(e) (ESI $\dagger$ ).

$$
\begin{gathered}
V_{\mathrm{c}} \sim 7 \times 10^{5} \mu \mathrm{m}^{3} \\
V_{\mathrm{p}} \sim 3 \times 10^{5} \mu \mathrm{m}^{3} \\
V_{\mathrm{s}}=0
\end{gathered}
$$

where $V_{\mathrm{c}}, V_{\mathrm{p}}$, and $V_{\mathrm{s}}$ are the volume of the center, peripheral, and top surface regions, respectively. $V_{\mathrm{s}}=0$ because the thickness is less than $1 \mu \mathrm{m}$. The numbers in parentheses in the average column in Table 1 correspond to the values determined in the previous paper to analyze the entire $\mathrm{Pd} / \mathrm{Al}_{2} \mathrm{O}_{3} \cdot{ }^{13}$ The average values agree with those determined by the analysis of the entire $\mathrm{Pd} / \mathrm{Al}_{2} \mathrm{O}_{3}$ region, validating the model shown in Fig. S1 (ESI $\dagger$ ).

More than $80 \%$ of the PdO particles in the peripheral region for Sel 0.9 and Sel 1.8 samples were reduced to Pd metal, as shown in Fig. 10, while nearly $50 \%$ of the Pd particles in the $\beta$ position were also reduced. Maybe the top surface region was too thin and the X-ray in the $\beta$ position may include the central region information.

Finally, we have proposed the model structure of $\mathrm{Pd} / \mathrm{Al}_{2} \mathrm{O}_{3}$ after degradation where $\mathrm{PdO}$ in the central region was covered with metallic Pd particles supported on $\mathrm{Al}_{2} \mathrm{O}_{3}$ in the peripheral and top surface regions, which are named as external regions hereafter. Such an inhomogeneous structure might have led to the effective deterioration of performance even though the majority of the Pd species was still in the PdO state. Interestingly the

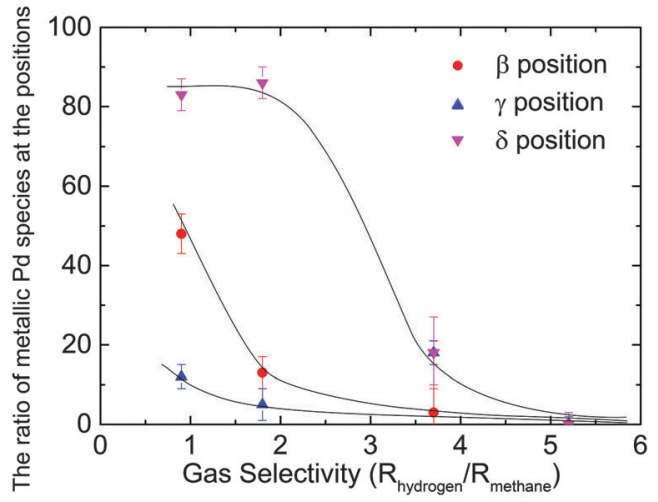

Fig. 10 Relationship between the ratio of metallic $\mathrm{Pd}$ species at the positions and selectivity.

metal distribution corresponded to the simulated temperature distribution. The temperature simulation showed that there was a temperature difference of $\sim 70 \mathrm{~K}$ between the $\mathrm{Pd} / \mathrm{Al}_{2} \mathrm{O}_{3}$ at the external regions and around the heater $(703 \mathrm{~K})$ as shown in Fig. S2 (ESI $\dagger$ ).

\section{Discussion}

Previous research showed that the $\mathrm{Pd} / \mathrm{Al}_{2} \mathrm{O}_{3}$ catalyst improved the selectivity of the sensor for methane ${ }^{6}$ and the formation of the Pd metal was related to the degradation of the sensor performance. ${ }^{13}$ The chemical state of $\mathrm{Pd}$ in $\mathrm{Pd} / \mathrm{Al}_{2} \mathrm{O}_{3}$ is an important factor to determine the response of the sensor toward methane and other gases. PdO is more active than Pd metal for other gases (such as hydrogen, alcohol, and carbon monoxide). ${ }^{6,26-28}$

Fig. 11 shows the degradation mechanism schematically. $\mathrm{PdO}$ in the $\mathrm{Pd} / \mathrm{Al}_{2} \mathrm{O}_{3}$ overlayer can burn out other gases more quickly than methane so that methane reaches the $\mathrm{SnO}_{2}$ sensor through the $\mathrm{Pd} / \mathrm{Al}_{2} \mathrm{O}_{3}$ overlayer because methane is the most inert gas. The formation of Pd metal in the external regions of the $\mathrm{Pd} / \mathrm{Al}_{2} \mathrm{O}_{3}$ overlayer changes the selectivity of the sensor for methane. The methane gas is combusted by the Pd metal in the external regions. Consequently, methane cannot reach the sensor part and the sensor selectivity for methane decreases
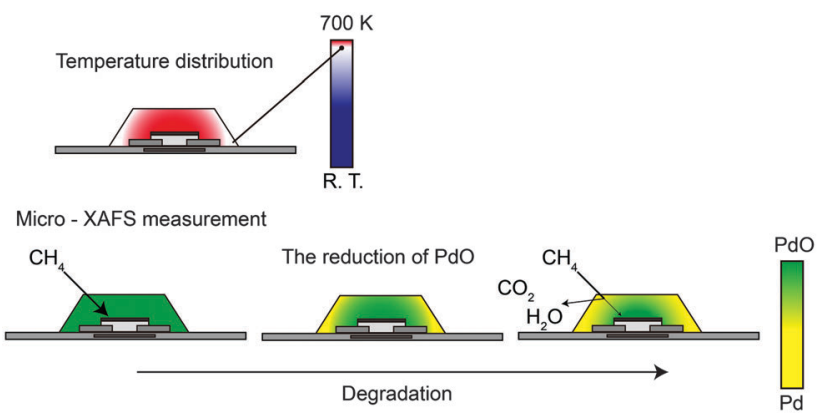

Fig. 11 Illustrations of the degradation mechanism and the $\mathrm{Pd} / \mathrm{Al}_{2} \mathrm{O}_{3}$ overlayer. 
tremendously, even if $\mathrm{PdO}$ is mainly present in the $\mathrm{Pd} / \mathrm{Al}_{2} \mathrm{O}_{3}$ catalyst overlayer. It is necessary to keep the PdO species in the external regions of the $\mathrm{Pd} / \mathrm{Al}_{2} \mathrm{O}_{3}$ overlayer for selective combustion and to increase the sensor selectivity. It is necessary that the Pd metal should not be present in the external parts of the sensor for selective combustion and to increase the sensor selectivity.

$\mathrm{Pd} / \mathrm{Al}_{2} \mathrm{O}_{3}$ in the external regions is more severely reduced than that in the central region because of the following two reasons: the first is that the regions are directly exposed to environmental gases, which always contain small amounts of reducing agents such as alcohol and oils. The second is that $\mathrm{Pd}$ is not heated up sufficiently to reach the desired temperature, say $\sim 703 \mathrm{~K}$. We carried out temperature dependent in situ XAFS measurements on the $\mathrm{Pd} / \mathrm{Al}_{2} \mathrm{O}_{3}$ film on $\mathrm{Si}$ under various atmospheres. We found that the PdO was partially reduced around $573 \mathrm{~K}$ in the $1000 \mathrm{ppm}_{2}$ containing air. The reduced PdO was reoxidized at more than $\sim 700 \mathrm{~K}^{29}$ In the real senor, the temperature in the external regions might be decreased by $10 \%$, which was not sufficient for the reoxidation. This work on $\mu$-XAFS has clearly demonstrated that in order to maintain the high performance of the sensor, the entire sensor must be heated to $703 \mathrm{~K}$. Pd metal has high activity to oxidize the methane, so it deteriorates the selectivity of the sensor for methane. We reported this $\mu$-XAFS to the factory and they devised a homogeneous heating method by the modification of the structure of the $\mathrm{Pd} / \mathrm{Al}_{2} \mathrm{O}_{3}$ overlayer. Consequently, the sensor lifetime has tremendously increased and reached a practically available level. ${ }^{13}$ In our previous study, ${ }^{13}$ we could not determine why small amounts of Pd metal species severely deteriorated the activity of the entire sensor, even though PdO was still a major component. Our present work on $\mu$-XAFS has shown that a $\mathrm{Pd}$ metal barrier formed in the external regions of the $\mathrm{Pd} / \mathrm{Al}_{2} \mathrm{O}_{3}$ overlayer effectively removed methane and hindered its arrival to the $\mathrm{SnO}_{2}$ layer. Consequently, the methane selectivity of the gas sensor decreased.

\section{Conclusions}

Each region in the real $\mu$-gas sensor was measured by $\mu$-XAFS using an X-ray $\mu$-beam made by a polycapillary lens. The methane selectivity of the sensor decreased with time under severe operation conditions. We found that the PdO of the sensor was inhomogeneously reduced, which decreased the methane selectivity of the sensor. The reduction of the Pd species mainly occurred in the external regions of the $\mathrm{Pd} / \mathrm{Al}_{2} \mathrm{O}_{3}$ overlayer. The Pd metal formed in the external regions combusted the methane gas completely, and hence, the methane gas could not approach the sensor part (i.e., the $\mathrm{SnO}_{2}$ thin layer). This work demonstrated that in order to understand the mechanism, it is important to analyze the inhomogeneity of the catalysts. The $\mu$-XAFS is a powerful analytical tool that gives structural information on the inhomogeneity of the sensor that helps in understanding the catalytic mechanism of a real device such as a $\mu$-gas sensor.

\section{Acknowledgements}

All XAFS measurements were conducted at the Photon Factory, KEK, (PAC no. 2012G680). The investigation was performed under the support of the New Energy and Industrial Technology Development Organization (NEDO). This work was supported by JSPS KAKENHI (Grant Number 24890061 and 15K20426).

\section{References}

1 Ministry of Economy, Trade and Industry, Japan's Energy White Paper 2014 (Japanese), 2014, 144-154.

22010 Energy Statistics Yearbook, http://unstats.un.org/ UNSD/energy/yearbook/default.htm, accessed Jun. 5.

3 C. X. Wang, L. W. Yin, L. Y. Zhang, D. Xiang and R. Gao, Sensors, 2010, 10, 2088-2106.

4 T. Suzuki, K. Kunihara, M. Kobayashi, S. Tabata, K. Higaki and H. Ohnishi, Sens. Actuators, B, 2005, 109, 185-189.

5 S. Tabata, K. Higaki, H. Ohnishi, T. Suzuki, K. Kunihara and M. Kobayashi, Sens. Actuators, B, 2005, 109, 190-193.

6 J. C. Kim, H. K. Jun, J.-S. Huh and D. D. Lee, Sens. Actuators, $B, 1997,45,271-277$.

7 N. Murata, T. Suzuki, M. Kobayashi, F. Togoh and K. Asakura, Phys. Chem. Chem. Phys., 2013, 15, 17938-17946.

8 N. Murata, M. Kobayashi, Y. Okada, T. Suzuki, H. Nitani, Y. Niwa, H. Abe, T. Wada, S. Mukai, H. Uehara, H. Ariga, S. Takakusagi and K. Asakura, Rev. Sci. Instrum., 2015, 86, 034102.

9 J.-D. Grunwaldt and A. Baiker, Catal. Lett., 2005, 99, 5-12.

10 J.-D. Grunwaldt, B. Kimmerle, A. Baiker, P. Boye, C. G. Schroer, P. Glatzel, C. N. Borca and F. Beckmann, Catal. Today, 2009, 145, 267-278.

11 M. Tada, N. Ishiguro, T. Uruga, H. Tanida, Y. Terada, S.-i. Nagamatsu, Y. Iwasawa and S.-i. Ohkoshi, Phys. Chem. Chem. Phys., 2011, 13, 14910-14913.

12 L. Mino, E. Borfecchia, C. Groppo, D. Castelli, G. MartinezCriado, R. Spiess and C. Lamberti, Catal. Today, 2014, 229, 72-79.

13 T. Wada, N. Murata, T. Suzuki, H. Uehara, H. Nitani, Y. Niwa, M. Uo and K. Asakura, Nano-Micro Lett., 2015, 7, 255-260.

14 M. Uo, K. Asakura, K. Watanabe and F. Watari, Chem. Lett., 2010, 39, 852-853.

15 T. Sugiyama, M. Uo, T. Wada, D. Omagari, K. Komiyama, T. Noguchi, Y. Jinbu and M. Kusama, BioMetals, 2015, 28, 11-20.

16 T. Sugiyama, M. Uo, T. Wada, D. Omagari, K. Komiyama, S. Miyazaki, C. Numako, T. Noguchi, Y. Jinbu, M. Kusama and Y. Mori, Sci. Rep., 2015, 5, 10672.

17 I. J. Pickering, R. C. Prince, D. E. Salt and G. N. George, Proc. Natl. Acad. Sci. U. S. A., 2000, 97, 10717-10722.

18 N. Fukuda, A. Hokura, N. Kitajima, Y. Terada, H. Saito, T. Abe and I. Nakai, J. Anal. At. Spectrom., 2008, 23, 1068-1075.

19 S. Kikuchi, H. Makita, S. Mitsunobu, Y. Terada, N. Yamaguchi, K. Takai and Y. Takahashi, Chem. Lett., 2011, 40, 680-681.

20 M. J. Pushie, I. J. Pickering, M. Korbas, M. J. Hackett and G. N. George, Chem. Rev., 2014, 114, 8499-8541. 
21 T. Suzuki, K. Onodera, F. Inoue and K. Tsuda, Jpn. Pat., JP3812215, 2006.

22 T. Suzuki, K. Onodera, F. Inoue and K. Tsuda, Jpn. Pat., P4376093, 2009.

23 M. Nomura, Y. Koike, M. Sato, A. Koyama, Y. Inada and K. Asakura, AIP Conf. Proc., 2007, 882, 896-898.

24 T. Taguchi, AIP Conf. Proc., 2007, 882, 162-164.

25 W. C. Hamilton, Acta Crystallogr., 1965, 18, 502-510.
26 T. Maillet, C. Solleau, J. Barbier Jr and D. Duprez, Appl. Catal., B, 1997, 14, 85-95.

27 V. Choudhary, A. Gaikwad and S. Sansare, Catal. Lett., 2002, 83, 235-239.

28 M. G. Jones, T. G. Nevell, R. J. Ewen and C. L. Honeybourne, Appl. Catal., 1991, 70, 277-286.

29 N. Murata, PhD dissertation, Hokkaido University, Hokkaido, Japan, 2016. 